\title{
The future of hydrology: An evolving science for a changing world
}

Thorsten Wagener, ${ }^{1}$ Murugesu Sivapalan, ${ }^{2,3,4}$ Peter A. Troch, ${ }^{5}$ Brian L. McGlynn, ${ }^{6}$

Ciaran J. Harman, ${ }^{3}$ Hoshin V. Gupta, ${ }^{5}$ Praveen Kumar, ${ }^{3}$ P. Suresh C. Rao, ${ }^{7}$

Nandita B. Basu, ${ }^{8}$ and Jennifer S. Wilson ${ }^{2}$

Received 15 November 2009; revised 17 February 2010; accepted 10 March 2010; published 12 May 2010.

[1] Human activities exert global-scale impacts on our environment with significant implications for freshwater-driven services and hazards for humans and nature. Our approach to the science of hydrology needs to significantly change so that we can understand and predict these implications. Such an adjustment is a necessary prerequisite for the development of sustainable water resource management strategies and to achieve long-term water security for people and the environment. Hydrology requires a paradigm shift in which predictions of system behavior that are beyond the range of previously observed variability or that result from significant alterations of physical (structural) system characteristics become the new norm. To achieve this shift, hydrologists must become both synthesists, observing and analyzing the system as a holistic entity, and analysts, understanding the functioning of individual system components, while operating firmly within a well-designed hypothesis testing framework. Cross-disciplinary integration must become a primary characteristic of hydrologic research, catalyzing new research and nurturing new educational models. The test of our quantitative understanding across atmosphere, hydrosphere, lithosphere, biosphere, and anthroposphere will necessarily lie in new approaches to benchmark our ability to predict the regional hydrologic and connected implications of environmental change. To address these challenges and to serve as a catalyst to bring about the necessary changes to hydrologic science, we call for a long-term initiative to address the regional implications of environmental change.

Citation: Wagener, T., M. Sivapalan, P. A. Troch, B. L. McGlynn, C. J. Harman, H. V. Gupta, P. Kumar, P. S. C. Rao, N. B. Basu, and J. S. Wilson (2010), The future of hydrology: An evolving science for a changing world, Water Resour. Res., 46, W05301, doi:10.1029/2009WR008906.

\section{Global Change Challenges}

[2] Human activities now rival geologic-scale forces [Kieffer, 2009], with a footprint that is deepening and widening rapidly across the planet (Figure 1) [Sanderson et al., 2002]. Manifestations of this footprint are visible in declining snowpacks resulting from human-induced climate change [Barnett et al., 2008], in quickly shrinking aquifer storages due to excessive pumping of groundwater [Rodell et al., 2009], in significantly distorted river flow regimes

\footnotetext{
${ }^{1}$ Department of Civil and Environmental Engineering, Pennsylvania State University, University Park, Pennsylvania, USA.

${ }^{2}$ Department of Geography, University of Illinois at Urbana-Champaign, Urbana, Illinois, USA.

${ }^{3}$ Department of Civil and Environmental Engineering, University of Illinois at Urbana-Champaign, Urbana, Illinois, USA.

${ }^{4}$ Department of Water Management, Delft University of Technology, Delft, Netherlands.

${ }^{5}$ Department of Hydrology and Water Resources, University of Arizona, Tucson, Arizona, USA.

${ }^{6}$ Department of Land Resources and Environmental Sciences, Montana State University, Bozeman, Montana, USA.

${ }^{7}$ School of Civil Engineering, Purdue University, West Lafayette, Indiana, USA.

${ }^{8}$ Department of Civil and Environmental Engineering, University of Iowa, Iowa City, Iowa, USA.
}

Copyright 2010 by the American Geophysical Union 0043-1397/10/2009WR008906 due to the building of dams [Poff et al., 2007], and in altered groundwater recharge due to changes in land use [Scanlon et al., 2006]. These are just a few examples of the humaninduced hydrologic change where demands of a growing population for energy [King et al., 2008], water [Jackson et al., 2001], food [Vörösmarty et al., 2000], and living space [Zhao et al., 2001] radically alter our environment. Many freshwater services we have historically relied on to protect our natural ecosystems and to provide for human needs are becoming irretrievably degraded as a consequence of human activity, at considerable cost to sustainability of both nature and human habitation [Palmer et al., 2004; Grimm et al., 2008; Brauman et al., 2007; Wagener et al., 2008]. The cumulative consequence of growing demand and a dwindling resource base is increased competition for a resource that is already scarce in many regions of the world, contributing to a decline in water security [Postel and Wolf, 2001; T. Allan, Avoiding war over natural resources, 1998, available from Global Policy Forum at http://www. globalpolicy.org/component/content/article/198/32890. $\mathrm{html}$. Together with this decline in freshwater services, we also face increases in hydrologic hazards such as floods and droughts due to an increase in hydrologic variability, especially in the least resilient of nations [Milly et al., 2002; Sheffield and Wood, 2008].

[3] Enabling society to address these problems, and to develop appropriate policies and management plans to 


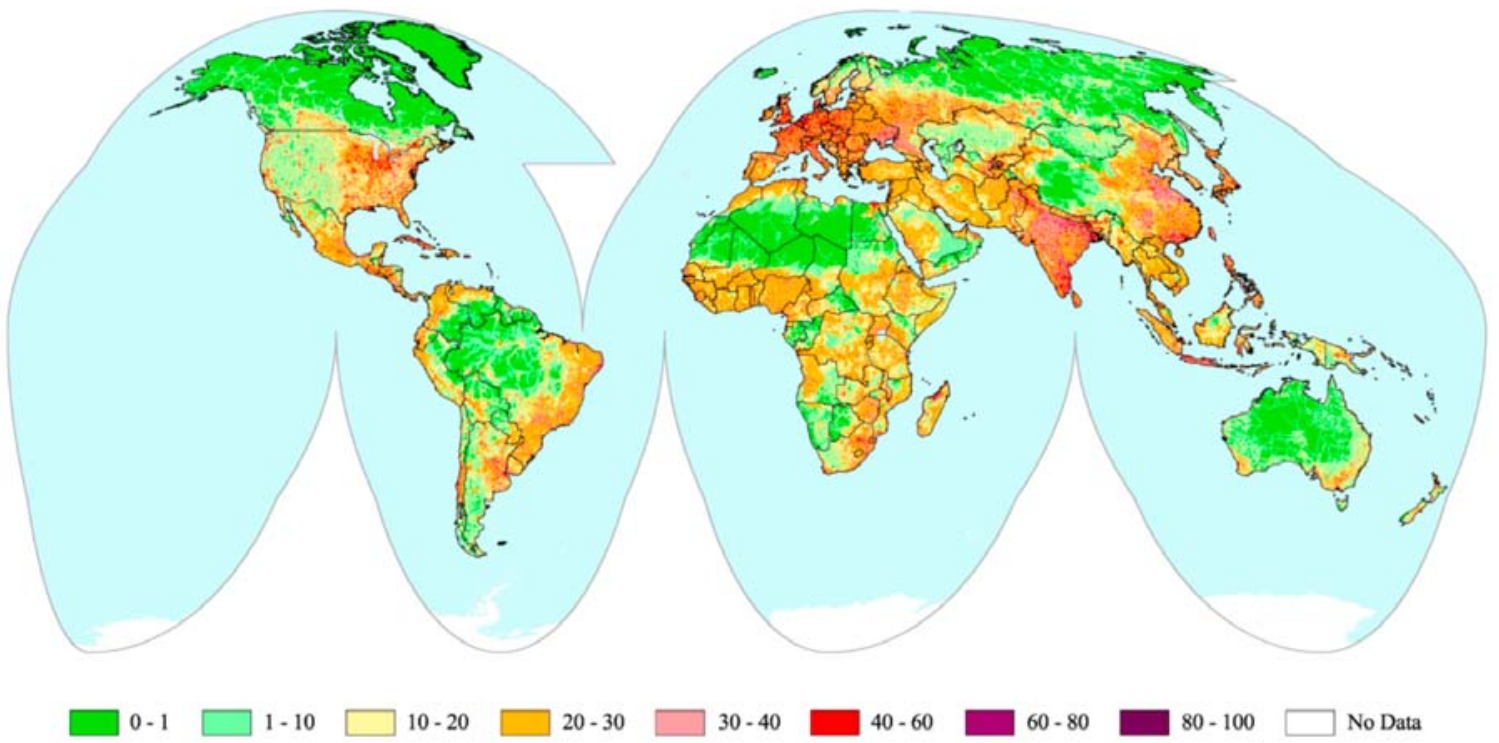

Figure 1. Sanderson et al. [2002] estimated the human footprint by quantifying how strongly humans impact the land surface, with a higher value of their human influence index indicating larger human impact (www.wcs.org/humanfootprint/). Their index integrates human population density, land transformation, human access, and electrical power infrastructure. Their study suggests that over $80 \%$ of the land surface is impacted by human activity [from Sanderson et al., 2002].

alleviate them, requires an ability to provide reliable predictions of freshwater occurrence, circulation, distribution, and quality under human-induced and natural change. To be robust and credible, such predictions must be underpinned by a greater understanding of the hydrologic and biogeochemical cycles and their interactions with land-forming and life-sustaining processes in the landscape, including an explicit treatment of the impacts of water-human-ecosystem interactions and associated feedbacks. Environmental management under global change requires new understanding of the connective and evolving role of water across a wide range of Earth and socioeconomic systems and across a wide range of time and space scales. This now poses enormous challenges to the conduct of hydrologic science [Killeen and Abrajano, 2008], requiring new ways to observe and analyze how our environment is changing because of both human and natural stressors and demanding new approaches to prediction and management.

\section{Challenges to Hydrologic Science}

[4] The main challenge facing hydrologic science is to deal with human-induced change. While the need to deal with the issue of change is not new to hydrology, the saving grace in most cases has (for a long time) been the availability of historical observations with which we could calibrate hydrologic models or from which we could extrapolate in time. This approach remains valid so long as system changes are not too severe [Sivapalan et al., 2003] and the critical assumption of stationarity can be justified [Milly et al., 2008]. Many of the research tools and educational materials adopted in the past have been founded on this assumption of stationarity. However, to make predictions in a changing environment, one in which the system structure may no longer be invariant or in which the system might exhibit previously unobserved behavior due to the exceedance of new thresholds, past observations can no longer serve as a sufficient guide to the future, and the credibility of our predictions cannot simply be achieved by reproducing historical observations. Instead, what is required is a greater consistency between model and real-world system, including new strategies to demonstrate this consistency [Gupta et al., 2008]. Historical observations of system characteristics and behavior will, of course, remain crucial to furthering understanding of hydrological processes and for evaluating process representations in models, although their value when moving beyond the range of observed behaviors is less clear and could possibly be much diminished.

[5] In an era of global change, the ability to respond appropriately to new societal needs and to make predictions at scales relevant to society will require us to develop a holistic and quantitative understanding of the changing (sometimes transient) behavior of hydrologic systems and their subsystems. Earth systems have coevolved over geologic timescales, and we can expect that they will continue to do so at potentially much greater rates because of human impacts (Figure 2). Predictions of hydrologic responses now need to allow for adaptive temporal evolution of vegetation, soils, and river networks (among other things) under human-induced environmental changes, although the changes might occur at different and varying rates. This requires hydrologists to develop a new understanding of how all the associated components (climate, soils, vegetation, and topography) have coevolved in the past and how they might do so in the future.

[6] Hydrology has made enormous strides in understanding the behavior of small, relatively homogeneous (and unchanging) systems (e.g., at the soil column or river reach level) over relatively short time scales, but more research is needed to understand hydrologic system complexity at 

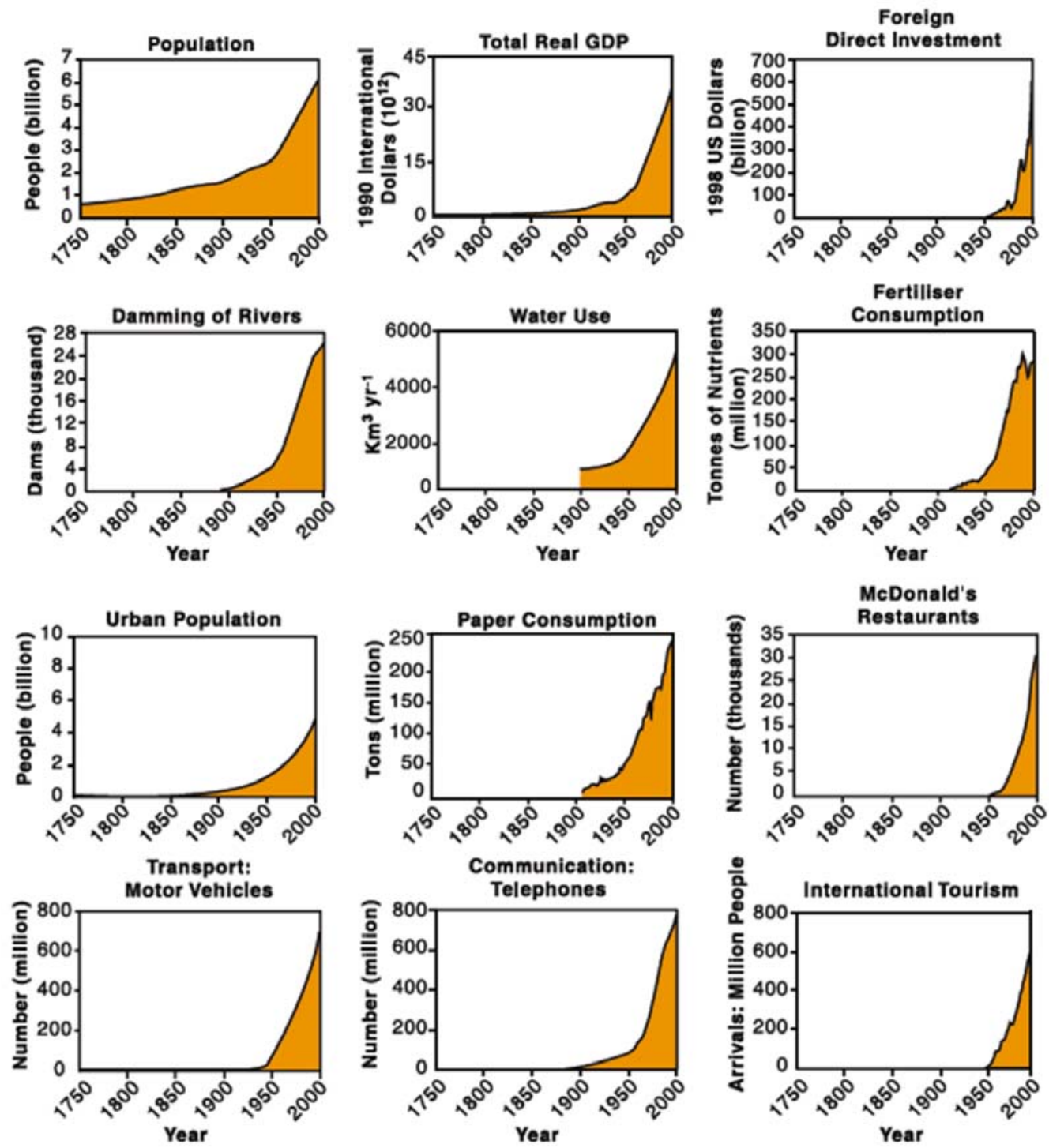

Figure 2. We see an unprecedented change in human activity, with often-unknown impacts on our environment and on the water cycle (from Steffen et al. [2004] with kind permission of Springer Science+Business Media).

larger scales (e.g., catchments, regional aquifers, river basins, and whole ecosystems), and over much longer time scales than we have typically addressed (e.g., decadal to century scales). System complexity under these circumstances arises from nonlinear, heterogeneous, and highly dynamic processes involving hydrologic, biogeochemical, ecologic, and human systems, with strong interactions and feedbacks, sometimes producing surprising behavior at larger scales [Gordon et al., 2008], not easily derived from understanding the components of the system in isolation. Lack of understanding of the complexity of whole-system behavior across space and time scales, combined with an inability to observe many of the systems' structural and functional characteristics and internal process dynamics (e.g., subsurface or stream network structures and processes and linkages between hydrologic, biogeochemical, and ecological processes), limits our ability to make hydrologic predictions at scales relevant to many societal challenges.
[7] One challenge in this regard is that such quantitative understanding will have to be generated even as measurement and monitoring resources are declining in many places [Mishra and Coulibaly, 2009]. Assessments of the implications of change also require an ability to benchmark the effects of change against earlier system states. It is particularly worrying that we have already lost track of the degree to which humans have changed the environment [Blackbourn, 2006; Walter and Merritts, 2008] and to what extent these changes are already reflected in the water cycle. This problem of shifting baselines (i.e., an ambiguity in identifying the correct baseline against which we should measure significant changes to the system) makes it even more difficult to assess the impacts of change [Pauly, 1995] (Figure 3).

\section{Hydrologic Change Science}

[8] Collectively, these challenges to hydrology call for profound changes in the ways we conduct hydrologic sci- 


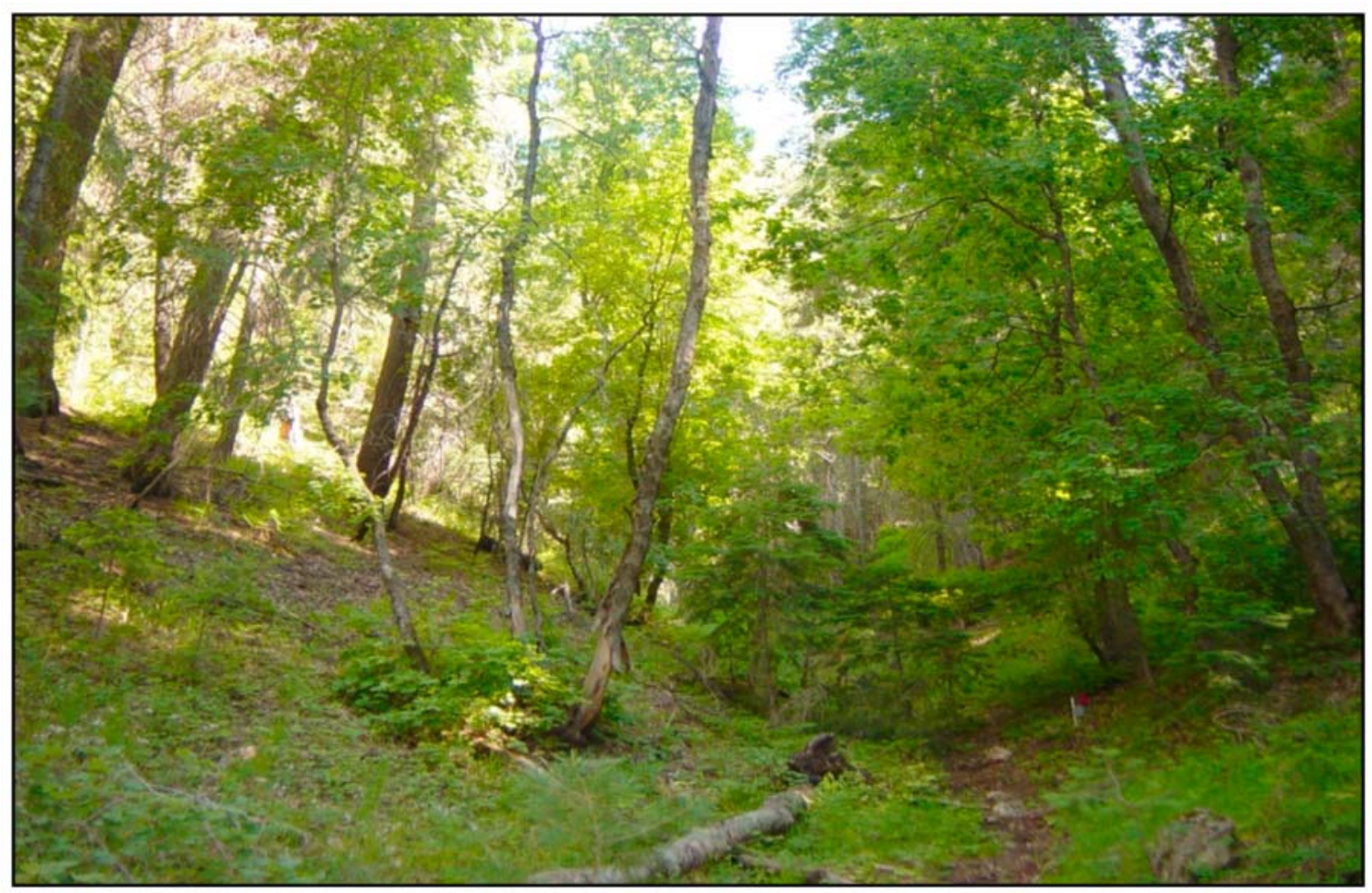

Figure 3. What is the baseline against which we measure the impacts of change? The photograph shows the Marshall Gulch catchment near Tucson in Arizona, United States. Does the current state of this system represent the natural baseline? (Photo taken by Craig Rasmussen.)

ence. Nonstationarity necessitates system evolution to be considered as an integral part of system behavior rather than as an exception [Vörösmarty et al., 2004; Milly et al., 2008], with significant challenges for observation and analyses to help understand and ultimately predict how the magnitudes of change will manifest themselves across scales and places [Heinz Center, 2008; Blöschl, 2006; Blöschl et al., 2007].

[9] Predicting the response of hydrologic systems in a changing environment requires that the water cycle be considered as a complex, interconnected system that includes not just the physical but also the biogeochemical, ecological, and human subsystems whose interactions contribute to land-forming (i.e., structure-forming) and life-sustaining processes. The complexity of the hydrologic system may be thought of as a series of hierarchies (Figure 4). At the most basic level (inner ring), water, nutrients, carbon, and sediments are characterized in terms of various fluxes, flow paths, stores, residence times, and state transformations (both physical and chemical). The nonlinear interactions between these components, through self-organization, give rise to emergent patterns in the landscape, such as river network structure, hydraulic geometry, soil catena, and vegetation patterns. Many models attempt to exploit these properties to improve predictability (middle ring). These units of conceptualization, through the understanding they generate, then form the basis for deciphering the interactions between human, physical, biogeochemical, and ecological systems that give rise to observed emergent patterns, identified here as units of engagement (outer ring). These interactions can, of course, cascade both ways. For example, human impacts modify extant patterns (e.g., stream network structure), which in turn alter flow paths, residence times (e.g., of nutrients, resulting in reduced denitrification), and physical and chemical transformations in the aquatic environment, ultimately impacting ecosystem health. It is evident that a variety of hierarchies and interfaces across disciplines exist that need to be understood, characterized, and modeled to predict the evolution of system behavior. A major scientific challenge is to understand how interacting processes have led to the structure and function of existing hydrologic systems and how they will evolve in the context of human-induced and natural changes to the environment [Wagener et al., 2007].

[10] In the past 20 years, under the umbrella of hydrogeomorphology and ecohydrology, hydrologists have made enormous progress in exploring a variety of interacting Earth surface processes, including hydrologic ones, involved in the coevolution of climate, soils, topography, and vegetation in natural settings [Rodriguez-Iturbe and Rinaldo, 1997; Rodriguez-Iturbe and Porporato, 2005; Eagleson, 2008]. This body of work has enabled significant advances toward a predictive understanding of the space-time structure and functioning of stream networks [e.g., Willgoose, 2005], vegetation [e.g., Rodriguez-Iturbe et al., 1999; Newman et $a l ., 2006$ ], and stream-vegetation interactions [e.g., Ivanov et al., 2008a, 2008b; Istanbulluoglu, 2009a]. A sound theoretical basis for learning from existing and readily available geomorphologic and vegetation patterns now exists, which can be used to predict likely future evolutionary changes [Porporato et al., 2004; Istanbulluoglu, 2009b] and their ecosystem impacts [e.g., Paola et al., 2006; Rodriguez-Iturbe et al., 2009]. This provides hope that a new generation of 


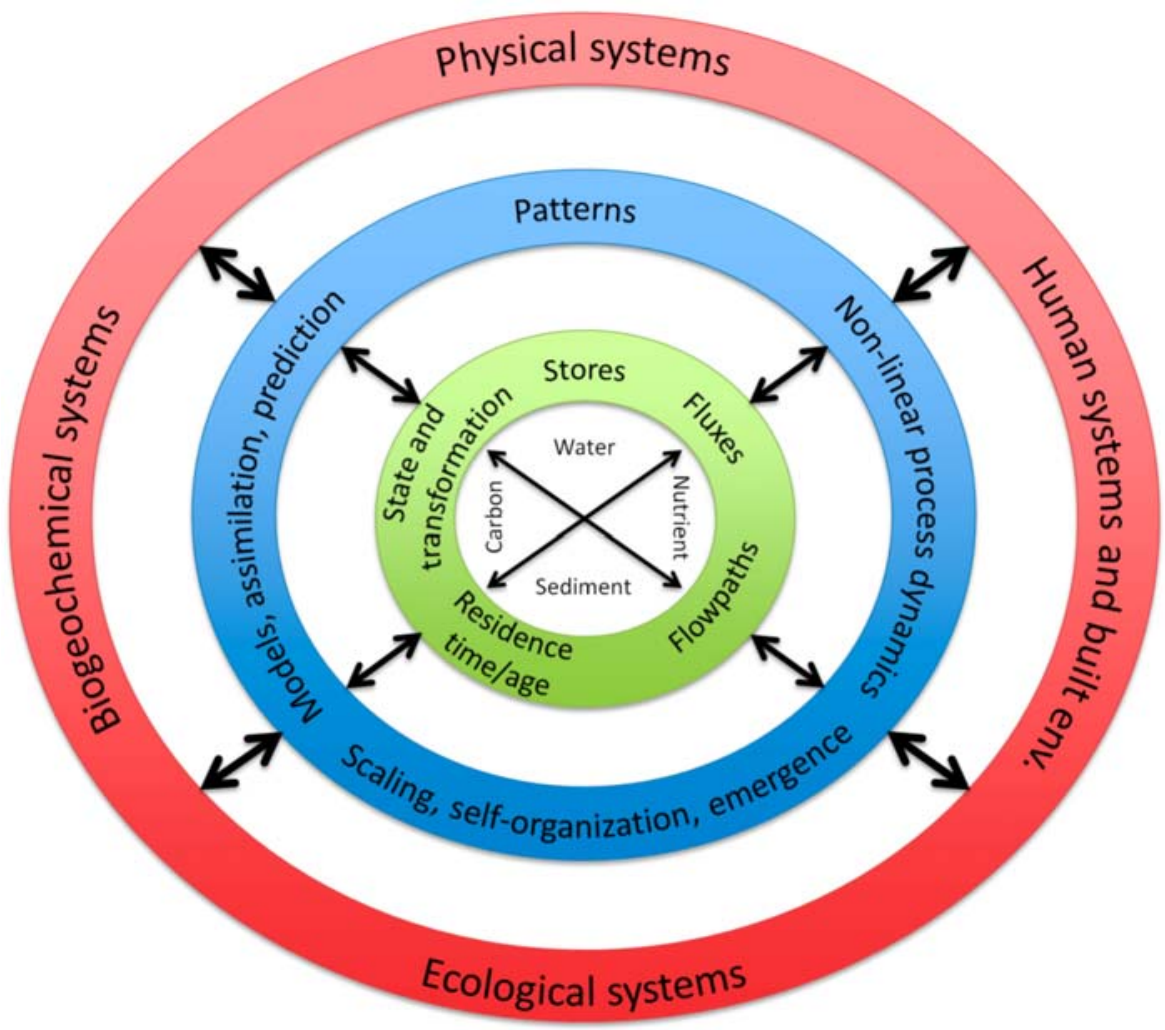

Figure 4. Hierarchies in coupled physical (oceans, atmosphere, rivers or lakes, and aquifers), ecological (habitats, disturbance regimes, and life cycles), biogeochemical (nutrient cycles, carbon cycle, and contaminants), and human (human impact, engineering works, water use, and management) subsystems that constitute the hydrological system: the innermost circle represents units of representation, the middle circle represents units of conceptualization, and the outer layer represents units of engagement (courtesy Praveen Kumar).

predictive models can be developed that incorporate organizing principles such as ecological optimality and minimum energy expenditure and basic thermodynamic principles such as maximum entropy production as a way to overcome the paucity of historical observations and inadequate characterization of landscape heterogeneity [McDonnell et al., 2007; Schymanski, 2008; Hwang et al., 2009; Kleidon and Schymanski, 2008].

[11] In light of the dominant role of humans in the landscape and their interference in the hydrologic cycle, the substantial progress made so far needs to be extended to human-impacted landscapes [Jackson et al., 2009]. Current and future experimental catchments must be embedded in larger-scale studies of hydrological variability and changing controls to aid in understanding the time scales over, and extent to which, system characteristics are changing. By embedding local (place-based) in-depth studies in the regional context, we can better understand (changing) hydrological behavior across environmental gradients. Such gradients form the basis of comparative hydrology [Falkenmark and Chapman, 1989], which attempts to understand how system behaviors and controls vary in space. An understanding of spatial variability can provide a firstorder assessment of potential temporal change by trading space for time [Wagener, 2007]. Given that long-range model projections suffer from large uncertainties, the strat- egy of using spatial gradients as proxy for temporal gradients might be an important first step [Troch et al., 2009]. Nevertheless, because of human interferences in the landscape, the character of many of the interactions and feedbacks that maintain the system in equilibrium may become irretrievably altered such that future system responses may diverge from what has been historically observed, imposing limits to what the past can tell us about the future [Kumar, 2007]. New observations must therefore include those that enable a deeper understanding of the legacy effects of past and future human behaviors and support understanding of human-induced emergent behaviors of hydrological systems across varying scales [Braden et al., 2009; Botter et al., 2010].

\section{Needs of an Evolving Science of Hydrologic Change}

[12] Human activity has impacted almost all parts of the landscape, so much so that hydrologic and human systems are now intrinsically coupled. Explicit recognition of this fact must move us toward a coherent holistic, quantitative, and predictive science of hydrology that is attuned to the needs of both nature and humans in a changing world. In recognizing the challenges of dealing with human-induced change so as to achieve a sustainable cohabitation of 
humans with nature, and in understanding the limitations of the current approach to hydrologic science, we arrive at certain broad questions that underpin the newly evolving science of hydrologic change.

[13] 1. How will the hydrologic system and its associated (sub)systems respond to, and evolve under, natural and human-induced changes in climate and the environment?

[14] 2. How are natural, managed, and engineered processes reflected in the various freshwater services that nature provides?

[15] 3. How can hydrologic systems be managed toward sustainability?

[16] Given such a perspective, the roles of current and future hydrologists must expand to seek greater understanding of how each system component receives, stores, transports, and releases water, energy, and dissolved and suspended constituents; how it interacts with the living world; and how it contributes to overall system behavior [McDonnell et al., 2007; Hopp et al., 2009; Dontsova et al., 2009]. Hydrologists need to work much more closely with experts from other disciplines, geologists, soil scientists, biologists, geochemists, ecologists, and social scientists, among others, to understand how the system functions at a much more fundamental level, as well as at the holistic level. This will promote a deeper understanding of the characteristics of the system, and of its components, under changing conditions. Through interdisciplinary collaborative efforts, a new balance can be struck between the reductionist and holistic approaches to experimental and theoretical (model-based) exploration of change. Hydrologists must become both synthesists, observing and analyzing the system as a holistic entity using top-down strategies, and analysts, understanding the functioning of individual system components through bottom-up approaches, while operating firmly from a strategy of well-designed hypothesis testing.

[17] The evolution of hydrologic science must also involve new kinds of observations (of processes and process interactions) and new ways to monitor and measure change. Remote sensing, for example, offers opportunities to measure environmental change at much larger scales than previously feasible, e.g., the GRACE mission to monitor changes in water storage [Rodell et al., 2009]. Observational strategies must explicitly consider the role of humans in the water cycle and must include measurements of water extraction for human use, return flow, water quality, and effects of infrastructure constructed to serve human needs. Modern technology facilitates the development of new (numerous, cheap, and qualitative yet useful) sensors and sensing techniques that can be used to monitor human water use and interactions with the water cycle (i.e., participatory sensing). This offers significant opportunities to improve system analyses and predictions via data-model fusion, realtime learning, and recursive forecasting. In comparison with the past, a greater use of controlled field and laboratory experiments across space and time scales is also needed [Kleinhans et al., 2010; Hopp et al., 2009; Holländer et al., 2009; Dontsova et al., 2009], which helps to improve our understanding of interacting processes under transient conditions. Further, a more opportunistic use of observations and monitoring in the aftermath of nature's experiments at larger scales in real landscapes (e.g., following accidents or natural disasters) can provide highly valuable data regarding extreme conditions [e.g., Jung et al., 2009].

[18] For hydrologic science to be better attuned to the needs of people, it must also be more explicitly connected to societal water uses and their ecosystem impacts. An understanding of the freshwater services provided by, and hazards arising from, hydrologic system responses must be explicitly linked to societal relevance and used to support sustainable resource management [Brauman et al., 2007; Wagener et al., 2008]. We must understand, and be able to project, the variability of such services under different scenarios, including their relationship to economic gains and losses [Clark et al., 2001]. There have been continental- or global-scale modeling assessments of water scarcity under projected climate change and population growth scenarios, which include increased water demand for food and energy production, and various technological and economical measures to increase resilience, e.g., the adoption of virtual water trade [Rockström et al., 2009; Liu et al., 2009]. Such analyses must contribute to understanding of the importance of green water fluxes and virtual water trade in support of regional decision making. Nevertheless, in doing so, the advancement of hydrologic understanding has to remain an important concern, and the adoption of tailored solutions that contribute little to hydrological innovation should be avoided since such solutions remain limited in their value as building blocks toward a coherent hydrologic theory. The importance of this focus on understanding has previously been discussed in the context of problem solving versus puzzle solving [Eagleson, 1991], which helps to contrast the engineering and scientific approaches to hydrologic research.

[19] Such a redirection of both effort and emphasis would help to fill current gaps in our understanding of coupled human-nature systems (examples of such gaps are poor understanding of nonlinear couplings and feedbacks and of scaling of hydrologic services), thereby addressing the significant challenges of characterizing evolutionary environmental change and the acceleration or deceleration of such change. It is abundantly clear that the sum total of such changes in our approach to hydrologic science (research, education, and practice) will constitute nothing less than a paradigm shift in the sense of a scientific revolution as described by Kuhn [1996]. Figure 5 presents a summary of the ideas that constitute key elements of the paradigm shift.

[20] Finally, it is not just the practice of hydrologic science that must become more holistic but also the approach to primary and continuing education of hydrologists. The educational system that supports the teaching of hydrology must undergo a paradigm shift away from the current practice of imparting a narrow set of basic concepts and a disciplinary set of skills to engineers and scientists. Given the great complexity of the problems facing a changing world, the teaching of hydrology must adopt a greater emphasis on learning from observations and from collective experiences in dealing with the environment around us (akin to the constructivist approach of Piaget [1967]). This calls for the teaching of new skill sets, including the ability to read, interpret, and learn from patterns in the landscape; comparative studies to supplement place-based studies; learning through case studies; use of space for time sub- 


\section{Current}

\section{Future}

\begin{tabular}{|c|c|}
\hline Humans are external to the hydrologic system & $\begin{array}{l}\text { Humans are intrinsic to the hydrologic system, both } \\
\text { as agents of change and as beneficiaries of } \\
\text { ecosystem services }\end{array}$ \\
\hline $\begin{array}{l}\text { Assumption of stationarity: past is a guide to the } \\
\text { future }\end{array}$ & $\begin{array}{l}\text { Nonstationary world: past is no longer a sufficient } \\
\text { guide to the future, expected variability could be } \\
\text { outside the range of observed variability }\end{array}$ \\
\hline $\begin{array}{l}\text { Predicting response, assuming fixed system } \\
\text { characteristics: boundary value problem with } \\
\text { prescribed fixed topography, soils, vegetation, } \\
\text { climate }\end{array}$ & $\begin{array}{l}\text { Both system and response evolve: no longer a } \\
\text { boundary value problem, boundary conditions and } \\
\text { interfaces themselves evolve and are coupled. } \\
\text { Becomes a complex adaptive system }\end{array}$ \\
\hline $\begin{array}{l}\text { Learning from studying individual places (often } \\
\text { pristine experimental catchments) to extrapolate or } \\
\text { upscale to other places }\end{array}$ & $\begin{array}{l}\text { Comparative hydrology: learning from individual } \\
\text { places embedded along gradients (e.g. changing } \\
\text { climate, human imprint) and across spatial scales }\end{array}$ \\
\hline $\begin{array}{l}\text { Hydrologists as analysts of individual processes or } \\
\text { features at small scales (akin to a microscope) or as } \\
\text { synthesists of whole system behavior at large scales } \\
\text { (akin to a telescope) }\end{array}$ & $\begin{array}{l}\text { Hydrologists as both analysts and synthesists (akin } \\
\text { to the macroscope) studying the coupled system } \\
\text { across a range of time and space scales }\end{array}$ \\
\hline $\begin{array}{l}\text { Observations to characterize input-output behavior } \\
\text { in individual (mostly) pristine places }\end{array}$ & $\begin{array}{l}\text { Observations to track the evolution of both structure } \\
\text { and response in coupled systems and subsystems }\end{array}$ \\
\hline $\begin{array}{l}\text { Observe and analyze pristine places and extrapolate } \\
\text { to make predictions of human impacts }\end{array}$ & $\begin{array}{l}\text { Observe and analyze real places where humans live } \\
\text { and interact with the hydrologic system at range of } \\
\text { scales }\end{array}$ \\
\hline $\begin{array}{l}\text { Model predictions derive credibility by reproducing } \\
\text { historical observations }\end{array}$ & $\begin{array}{l}\text { Model predictions derive credibility via more in-depth } \\
\text { diagnostic evaluation of model consistency with } \\
\text { underlying system and testing of behavior outside of } \\
\text { observed range }\end{array}$ \\
\hline $\begin{array}{l}\text { Observation, prediction (modeling) and management } \\
\text { are separate exercises (without feedbacks!) }\end{array}$ & $\begin{array}{l}\text { Real-time learning: observations (sensing, including } \\
\text { participatory human sensing), modeling and } \\
\text { management are interactive exercises with } \\
\text { feedbacks and updating }\end{array}$ \\
\hline $\begin{array}{l}\text { Strong separation between engineering and science } \\
\text { approaches to hydrology education }\end{array}$ & $\begin{array}{l}\text { Integration of qualitative and quantitative aspects } \\
\text { into a holistic teaching of hydrology }\end{array}$ \\
\hline $\begin{array}{l}\text { Focus on teaching established solutions to } \mathrm{c} \\
\text { problems }\end{array}$ & $\begin{array}{l}\text { Focus on teaching of evolving skill sets with a strong } \\
\text { scientific basis that can be adapted to solving new } \\
\text { problems and to understanding new phenomena }\end{array}$ \\
\hline
\end{tabular}

Figure 5. Key elements of the needed paradigm shift in hydrologic science (building on work by Sivapalan [2005]).

stitutions; and modeling of interacting processes such as human-nature interactions and feedbacks. Above all, the new generation of hydrologists must be trained to become both analysts and synthesists. This will inevitably require dissolution of the historical separation between science and engineering in our approach to hydrology education. Teaching methods should be rooted in the scientific and quantitative understanding of hydrologic processes, providing flexible hydrologic problem-solving skills, which can be adapted to provide solutions for new problems and to understand new phenomena. For our science to evolve, these skills must necessarily continue to advance, which provides new challenges to the continuing education of practicing hydrologists. Kleinhans et al. [2010] argue that it is necessary for hydrology and other Earth sciences to go beyond the traditional inductive and deductive lines of reasoning by adopting a formalized use of observed patterns and known laws of nature to arrive at hypotheses on the causes of these patterns, in this way arriving at improved understanding. Hydrology education can benefit from recognition of this logical style of reasoning. While these arguments provide some perspective on the kind of paradigm shift that appears to be needed in hydrology education, a considerable new effort at the community level will be required toward the joint development and continuing evolution of holistic education materials and to promote the mutual exchange of experiences as a community of teachers and practitioners (Modular Curriculum for Hydrological Advancement (MOCHA), 2009, http://www.mocha.psu.edu).

\section{Call to Action}

[21] The problems of water scarcity, environmental degradation, and water-related natural hazards arising from the expansion of the human imprint on Earth pose enormous challenges to the way we conduct hydrologic science. 
However, they also provide an unprecedented opportunity to utilize technological and theoretical advances in measurement, modeling, and visualization of both variability and change in our world, these being prerequisites for detecting, interpreting, predicting, and managing evolving hydrologic systems. By addressing these challenges, we can help to bring about a paradigm shift in hydrologic science by fundamentally revising and advancing the concepts, theories, and methodologies that underpin our science.

[22] How do we, as a community, facilitate this paradigm shift? What are some of the actions we can undertake to help evolve our science? We believe that the required scientific revolution can best be achieved by a grass roots-driven and community-led long-term initiative that focuses on the regional implications of change (in climate, land cover, land use, and population), thereby providing the catalyst needed to bring about the change we believe is required. The quest to achieve better regional-scale predictions will help to uncover deficiencies in our quantitative understanding and in our ability to provide information at the scales most relevant for decision making. We believe that it will only be through a cross-disciplinary long-term community effort (involving hydrology and other Earth as well as the biological and social sciences), with a unified focus on the regional implications of environmental change, that the required fundamental transformation of our science can be achieved. Significant progress has already been made in strengthening interdisciplinary collaboration across the Earth sciences. In addition to this, we are now poised to capitalize on recent advances in the technological ability to observe, store, analyze, visualize, and transmit relevant data collected over large parts of the world at appropriately fine resolutions.

[23] Examples of where such community-driven initiatives have brought about greater focus and coherence to hydrologic research, teaching, and practice abound. The First International Hydrologic Decade led to the launch of a large number of experimental basins around the world, which brought about major advances in data collection and process understanding [Keller, 1976]. The recent Predictions in Ungauged Basins (PUB) decadal initiative of the International Association of Hydrological Sciences launched in 2002 [Sivapalan et al., 2003] quickly went far beyond a dependence of predictive models on calibration, and highlighted limitations in theory, in the ability to observe and predict and ultimately in our capacity to assess the hydrologic implications of environmental change [Sivapalan, 2003; Blöschl, 2006; Kirchner, 2006; Wagener, 2007; Troch et al., 2008]. By elevating the profile of the fundamental question of how to transfer information from one location to another and from gauged to ungauged catchments, PUB led to a sharper focus in research, energized the hydrologic community, enhanced integration across disciplines and subdisciplines, and is bringing about significant advancements and greater coherence in our understanding of catchment responses and our ability to predict them. Driven by the increasing speed of environmental change, the proposed new initiative must shift the focus from extrapolating in space to extrapolating in time (using space for time proxies as appropriate) by creating a particular emphasis on the regional implications of global and local change. This will help provide guidance for adaptation efforts, as it is at the regional scale that human decision making and environmental stresses intersect [Barron, 2009].

[24] Acknowledgments. This is a contribution of the "hydrologic synthesis" project led by the University of Illinois and funded by NSF under EAR-0636043, Water Cycle Dynamics in a Changing Environment: Advancing Hydrologic Science through Synthesis, and of NSF project EAR-0635998, Understanding the Hydrologic Implications of Landscape Structure and Climate-Toward a Unifying Framework of Watershed Similarity. We would like to thank Tom Torgersen (Editor), Günter Blöschl, Scott Tyler, and an anonymous reviewer for their constructive criticism that resulted in significant improvements to this paper.

\section{References}

Barnett, T. P., et al. (2008), Human-induced changes in the hydrology of the western United States, Science, 319, 1080-1083, doi:10.1126/science. 1152538 .

Barron, E. J. (2009), Beyond climate science, Science, 326, 643, doi:10.1126/science. 1179807 .

Blackbourn, D. (2006), The Conquest of Nature: Water, Landscape, and the Making of Modern Germany, Jonathan Cape, London.

Blöschl, G. (2006), Hydrologic synthesis: Across processes, places, and scales, Water Resour. Res., 42, W03S02, doi:10.1029/2005WR004319.

Blöschl, G., S. Ardoin-Bardin, M. Bonell, M. Dorninger, D. Goodrich, D. Gutknecht, D. Matamoros, B. Merz, P. Shand, and J. Szolgay (2007), At what scales do climate variability and land cover change impact on flooding and low flows?, Hydrol. Processes, 21, 1241-1247, doi:10.1002/hyp.6669.

Botter, G., S. Basso, A. Porporato, I. Rodriguez-Iturbe, and A. Rinaldo (2010), Natural streamflow regime alterations: The damming of the Piave River basin (Italy), Water Resour. Res., doi:10.1029/2009WR008523, in press.

Braden, J. B., et al. (2009), Social science in a water observing system, Water Resour. Res., 45, W11301, doi:10.1029/2009WR008216.

Brauman, K. A., G. C. Daily, K. Duarte, and H. A. Mooney (2007), The nature and value of ecosystem services: An overview highlighting hydrologic services, Annu. Rev. Environ. Resour., 32, 67-98, doi:10.1146/ annurev.energy.32.031306.102758.

Clark, J. S., et al. (2001), Ecological forecasts: An emerging paradigm, Science, 293, 657-660, doi:10.1126/science.293.5530.657.

Dontsova, K., C. I. Steefel, S. Desilets, A. Thompson, and J. Chorover (2009), Solid phase evolution in the Biosphere 2 hillslope experiment as predicted by modeling of hydrologic and geochemical fluxes, Hydrol. Earth Syst. Sci., 13, 2273-2286.

Eagleson, P. S. (1991), Opportunities in the Hydrologic Sciences, Natl. Acad. Press, Washington, D. C.

Eagleson, P. S. (2008), Ecohydrology: Darwinian Expression of Vegetation Form and Function, Cambridge Univ. Press, U. K.

Falkenmark, M., and T. Chapman (1989), Comparative Hydrology-An Ecological Approach to Land and Water Resources, 479 pp., U.N. Educ., Sci. and Cult. Organ., Paris.

Gordon, L. J., G. D. Peterson, and E. M. Bennett (2008), Agricultural modifications of hydrologic flows create ecological surprises, Trends Ecol. Evol., 23(4), 211-219, doi:10.1016/j.tree.2007.11.011.

Grimm, N. B., S. H. Faeth, N. E. Golubiewski, C. L. Redman, J. Wu, X. Bai, and J. M. Briggs (2008), Global change and the ecology of cities, Science, 319, 756-760, doi:10.1126/science.1150195.

Gupta, H. V., T. Wagener, and Y. Liu (2008), Reconciling theory with observations: Elements of a diagnostic approach to model evaluation, Hydrol. Processes, 22, 3802-3813, doi:10.1002/hyp.6989.

Heinz Center (2008), Environmental information: A road map to the future, report, Washington D. C.

Holländer, H. M., et al. (2009), Comparative predictions of discharge from an artificial catchment (Chicken Creek) using sparse data, Hydrol. Earth Syst. Sci., 13, 2069-2094.

Hopp, L., C. J. Harman, S. L. E. Desilets, C. B. Graham, J. J. McDonnell, and P. A. Troch (2009), Hillslope hydrology under glass: Confronting fundamental questions of soil-water-biota co-evolution at Biosphere 2, Hydrol. Earth Syst. Sci., 13, 2105-2118.

Hwang, T., L. Band, and T. C. Hales (2009), Ecosystem processes at the watershed scale: Extending optimality theory from plot to catchment, Water Resour. Res., 45, W11425, doi:10.1029/2009WR007775.

Istanbulluoglu, E. (2009a), An eco-hydro-geomorphic perspective to modeling the role of climate in catchment evolution, Geogr. Compass, 3, 1151-1175, doi:10.1111/j.1749-8198.2009.00229.x. 
Istanbulluoglu, E. (2009b), Modeling catchment evolution: From decoding geomorphic processes signatures toward predicting impacts of climate change, Geogr. Compass, 3, 1125-1150, doi:10.1111/j.1749-8198. 2009.00228.X.

Ivanov, V. Y., R. L. Bras, and E. R. Vivoni (2008a), Vegetation-hydrology dynamics in complex terrain of semiarid areas: 1. A mechanistic approach to modeling dynamic feedbacks, Water Resour. Res., 44, W03429, doi:10.1029/2006WR005588.

Ivanov, V. Y., R. L. Bras, and E. R. Vivoni (2008b), Vegetation-hydrology dynamics in complex terrain of semiarid areas: 2. Energy-water controls of vegetation spatiotemporal dynamics and topographic niches of favorability, Water Resour. Res., 44, W03430, doi:10.1029/2006WR005595.

Jackson, R. B., S. R. Carpenter, C. N. Dahm, D. M. McKnight, R. J. Naiman, S. L. Postel, and S. W. Running (2001), Water in a changing world, Ecol. Appl., 11, 1027-1045, doi:10.1890/1051-0761(2001)011 [1027:WIACW]2.0.CO;2.

Jackson, R. B., E. G. Jobbagy, and M. D. Nosetto (2009), Ecohydrology in a human-dominated landscape, Ecohydrology, 2, 383-389, doi:10.1002/ eco.81.

Jung, H. Y., T. S. Hogue, L. K. Rademacher, and T. Meixner (2009), Impact of wildfire on source water contributions in Devil Creek, CA: Evidence from end-member mixing analysis, Hydrol. Processes, 23, 183-200, doi:10.1002/hyp.7132.

Keller, R. (1976), The international hydrological decade-The international hydrological programme, Geoforum, 7(2), 139-143, doi:10.1016/00167185(76)90008-7.

Kieffer, S. (2009), Celebrating the Earth: Its past, our present, a future?, paper presented at AAAS Congress, Am. Assoc. for the Adv. of Sci., Chicago, Ill.

Killeen, T. L. and T. Abrajano (2008), Understanding the triple point, Elements, October, 298.

King, C. W., A. S. Holman, and M. E. Webber (2008), Thirst for energy, Nat. Geosci., 1(5), 283-286, doi:10.1038/ngeo195.

Kirchner, J. W. (2006), Getting the right answers for the right reasons: Linking measurements, analyses, and models to advance the science of hydrology, Water Resour. Res., 42, W03S04, doi:10.1029/ 2005WR004362.

Kleidon, A., and S. J. Schymanski (2008), Thermodynamics and optimality of the water budget on land: A review, Geophys. Res. Lett., 35, L20404, doi:10.1029/2008GL035393.

Kleinhans, M. G., M. F. P. Bierkens, and M. And van der Perk (2010), On the use of laboratory experimentation: "Hydrologists, bring out shovels and garden hoses and hit the dirt", Hydrol. Earth Syst. Sci., 14, 369-382.

Kuhn, T. S. (1996), The Structure of Scientific Revolutions, 3rd ed., Univ. of Chicago Press, Chicago, Ill.

Kumar, P. (2007), Variability, feedback, and cooperative process dynamics: Elements of a unifying hydrologic theory, Geogr. Compass, 1, 1338-1360, doi:10.1111/j.1749-8198.2007.00068.x.

Liu, J., A. J. B. Zehnder, and H. Yang (2009), Global consumptive water use for crop production: The importance of green water and virtual water, Water Resour. Res., 45, W05428, doi:10.1029/2007WR006051.

McDonnell, J. J., et al. (2007), Moving beyond heterogeneity and process complexity: A new vision for watershed hydrology, Water Resour. Res., 43, W07301, doi:10.1029/2006WR005467.

Milly, P. C. D., R. T. Wetherald, K. A. Dunne, and T. L. Delworth (2002), Increasing risk of great floods in a changing climate, Nature, 415, 514-517, doi:10.1038/415514a.

Milly, P. C. D., J. Betancourt, M. Falkenmark, R. M. Hirsch, Z. W. Kundzewicz, D. P. Lettenmaier, and R. J. Stouffer (2008), Stationarity is dead: Whither water management?, Science, 319, 573-574, doi:10.1126/science.1151915.

Mishra, A. K., and P. Coulibaly (2009), Developments in hydrometric network design: A review, Rev. Geophys., 47, RG2001, doi:10.1029/ 2007RG000243.

Newman, B. D., B. P. Wilcox, S. R. Archer, D. D. Breshears, C. N. Dahm, C. J. Duffy, N. G. McDowell, F. M. Phillips, B. R. Scanlon, and E. R. Vivoni (2006), Ecohydrology of water-limited environments: A scientific vision, Water Resour. Res., 42, W06302, doi:10.1029/2005WR004141.

Palmer, M., et al. (2004), Ecology for a crowded planet, Science, 304, 1251-1252, doi:10.1126/science. 1095780 .

Paola, C., E. Foufoula-Georgiou, W. E. Dietrich, M. Hondzo, D. Mohrig, G. Parker, M. E. Power, I. Rodriguez-Iturbe, V. Voller, and P. Wilcock (2006), Toward a unified science of the Earth's surface: Opportunities for synthesis among hydrology, geomorphology, geochemistry, and ecology, Water Resour. Res., 42, W03S10, doi:10.1029/ 2005WR004336.
Pauly, D. (1995), Anecdotes and the shifting baseline syndrome of fisheries, Trends Ecol. Evol., 10(10), 430, doi:10.1016/S0169-5347 (00)89171-5.

Piaget, J. (1967), Logique et Connaissance Scientifique, Encycl. Pleiade, vol. 22 , Gallimard, Paris.

Poff, N. L., J. D. Olden, D. Merritt, and D. Pepin (2007), Homogenization of regional river dynamics by dams and global biodiversity implications, Proc. Natl. Acad. Sci. U. S. A., 104, 5732-5737, doi:10.1073/pnas. 0609812104.

Porporato, A., E. Daly, and I. Rodriguez-Iturbe (2004), Water balance and ecosystem response to climate change, Am. Nat., 164(5), 625-632, doi:10.1086/424970.

Postel, S. L., and A. T. Wolf (2001), Dehydrating conflict, Foreign Policy, 9, 60-67.

Rockström, J., M. Falkenmark, L. Karlberg, H. Hoff, and S. Rost (2009), The potential of green water for increasing resilience to global change, Water Resour. Res., 45, W00A12, doi:10.1029/2007WR006767.

Rodell, M., I. Velicogna, and J. S. Famiglietti (2009), Satellite-based estimates of groundwater depletion in India, Nature, 460, 999-1002, doi: 10.1038 /nature08238.

Rodriguez-Iturbe, I., and A. Porporato (2005), Ecohydrology of WaterControlled Ecosystems: Soil Moisture and Plant Dynamics, 460 pp., Cambridge Univ. Press, Cambridge, U. K.

Rodriguez-Iturbe, I., and A. Rinaldo (1997), Fractal River Basins: Chance and Self-Organization, 564 pp., Cambridge Univ. Press, Cambridge, U. K.

Rodriguez-Iturbe, I., P. D’Odorico, A. Porporato, and L. Ridolfi (1999), On the spatial and temporal links between vegetation, climate, and soil moisture, Water Resour. Res., 35(12), 3709-3722, doi:10.1029/ 1999WR900255.

Rodriguez-Iturbe, I., R. Muneepeerakul, E. Bertuzzo, S. A. Levin, and A. Rinaldo (2009), River networks as ecological corridors: A complex systems perspective for integrating hydrologic, geomorphologic, and ecologic dynamics, Water Resour. Res., 45, W01413, doi:10.1029/2008WR007124.

Sanderson, E. W., M. Jaiteh, M. A. Levy, K. H. Redford, A. V. Wannebo, and G. Woolmer (2002), The human footprint and the last of the wild, BioScience, 52, 891-904, doi:10.1641/0006-3568(2002)052[0891: THFATL]2.0.CO;2.

Scanlon, B. R., K. E. Keese, A. L. Flint, L. E. Flint, C. B. Gaye, M. Edmunds, and I. Simmers (2006), Global synthesis of groundwater recharge in semiarid and arid regions, Hydrol. Processes, 20 , 3335-3370, doi:10.1002/hyp.6335.

Schymanski, S. J. (2008), Optimality as a concept to understand and model vegetation at different scales, Geogr. Compass, 2, 1580-1598, doi:10.1111/j.1749-8198.2008.00137.x.

Sheffield, J., and E. F. Wood (2008), Projected changes in drought occurrence under future global warming from multi-model, multi-scenario, IPCC AR4 simulations, Clim. Dyn., 31, 79-105, doi:10.1007/s00382007-0340-z.

Sivapalan, M. (2003), Prediction in ungauged basins: A grand challenge for theoretical hydrology, Hydrol. Processes, 17, 3163-3170, doi:10.1002/ hyp. 5155.

Sivapalan, M. (2005), Pattern, process and function: Elements of a unified theory of hydrology at the catchment scale, in Encyclopedia of Hydrological Sciences, edited by M. G. Anderson, pp. 193-219, John Wiley, London.

Sivapalan, M., et al. (2003), IAHS decade on predictions in ungauged basins (PUB), 2003-2012: Shaping an exciting future for the hydrological sciences, Hydrol. Sci. J., 48(6), 857-880, doi:10.1623/ hysj.48.6.857.51421.

Steffen, W., et al. (2004), Global Change and the Earth System: A Planet Under Pressure, Springer, Berlin.

Troch, P. A., G. A. Carrillo, I. Heidbuechel, S. Rajagopal, M. Switanek, T. H. M. Volkmann, and M. A. Yaeger (2008), Dealing with landscape heterogeneity in watershed hydrology: A review of recent progress toward new hydrological theory, Geogr. Compass, 3, 375-392, doi:10.1111/ j.1749-8198.2008.00186.x.

Troch, P. A., G. F. Martinez, V. R. N. Pauwels, M. Durcik, M. Sivapalan, C. J. Harman, P. D. Brooks, H. V. Gupta, and T. E. Huxman (2009), Climate and vegetation water-use efficiency at catchment scales, Hydrol. Processes, 23, 2409-2414, doi:10.1002/hyp.7358.

Vörösmarty, C. J., P. Green, J. Salisbury, and R. B. Lammers (2000), Global water resources: Vulnerability from climate change and population growth, Science, 289, 284-288, doi:10.1126/science.289.5477.284.

Vörösmarty, C. J., D. Lettenmaier, C. Leveque, M. Meybeck, C. Pahl-Wostl, J. Alcamo, H. Cosgrove, H. Grassl, H. Hoff, and P. Kabat (2004), Humans 
transforming the global water system, Eos Trans. $A G U, 85(48), 509$, doi:10.1029/2004EO480001.

Wagener, T. (2007), Can we model the hydrologic implications of environmental change?, Hydrol. Processes, 21, 3233-3236, doi:10.1002/ hyp. 6873 .

Wagener, T., M. Sivapalan, P. A. Troch, and R. A. Woods (2007), Catchment classification and hydrologic similarity, Geogr. Compass, 1, 901-931, doi:10.1111/j.1749-8198.2007.00039.x.

Wagener, T., M. Sivapalan, and B. McGlynn (2008), Catchment classification and services - Toward a new paradigm for catchment hydrology driven by societal needs, in Encyclopedia of Hydrological Sciences, edited by M. G. Anderson, John Wiley, Chichester, U. K.

Walter, R. C., and D. J. Merritts (2008), Natural streams and the legacy of water-powered mills, Science, 319, 299-304, doi:10.1126/science. 1151716.

Willgoose, G. (2005), Mathematical modeling of whole landscape evolution, Annu. Rev. Earth Planet. Sci., 33, 443-459, doi:10.1146/annurev. earth.33.092203.122610.
Zhao, M., A. J. Pitman, and T. N. Chase (2001), The impact of land cover on the atmospheric circulation, Clim. Dyn., 17, 467-477, doi:10.1007/ PL00013740.

N. B. Basu, Department of Civil and Environmental Engineering, University of Iowa, Iowa City, IA 52242, USA.

H. V. Gupta and P. A. Troch, Department of Hydrology and Water Resources, University of Arizona, Tucson, AZ 85721-0011, USA.

C. J. Harman and P. Kumar, Department of Civil and Environmental Engineering, University of Illinois at Urbana-Champaign, Urbana, IL 61801, USA.

B. L. McGlynn, Department of Land Resources and Environmental Sciences, Montana State University, Bozeman, MT 59717-3120, USA.

P. S. C. Rao, School of Civil Engineering, Purdue University, West Lafayette, IN 47907-2051, USA.

M. Sivapalan and J. S. Wilson, Department of Geography, University of Illinois at Urbana-Champaign, Urbana, IL 61801, USA.

T. Wagener, Department of Civil and Environmental Engineering, Pennsylvania State University, 231F Sackett Bldg., University Park, PA 16802, USA. (thorsten@engr.psu.edu) 